\title{
Chloride Uptake by Mycelium of Neocosmospora vasinfecta and Its Inhibition by Glucose
}

\author{
By A. G. MILLER AND K. BUDD \\ Biology Department, Queen's University, Kingston, Ontario, Canada
}

(Accepted for publication 5 April I97I)

\begin{abstract}
Studies of the transport of inorganic ions by fungi have lagged behind those of most other groups of organisms. In the yeast Saccharomyces cerevisiae, which is the exception to this statement, most attention has been focused on cation transport: absorption of $\mathrm{PO}_{4}^{3-}$ and $\mathrm{SO}_{4}^{2-}$ has been examined, but the organism 'behaves as though impermeable to $\mathrm{Cl}^{-}$' (Rothstein, 1965; cf. Conway \& Downey, 1950). However, during $\mathrm{K}^{+}$uptake by the mycelial ascomycete Neocosmospora vasinfecta net $\mathrm{Cl}^{-}$absorption also takes place, though not at the same rate (Budd, $1969 a$ ). This report confirms the absorption of $\mathrm{Cl}^{-}$in this organism and describes the effect of extracellular glucose on this process.
\end{abstract}

\section{METHODS}

Mycelium of Neocosmospora vasinfecta E. F. Smith (ATCC I I68I ; American Type Culture Collection, Rockville, Maryland, U.S.A.) was grown in submerged culture in the Gl medium of Budd $(\mathrm{I} 969 \mathrm{~b})$ which contained only contaminant amounts of $\mathrm{Cl}^{-}$. It was harvested by filtration, washed thoroughly in demineralized water, preincubated in aerated, demineralized water for 3 to $4 \mathrm{~h}$. then filtered and resuspended, at a density of approximately $150 \mathrm{mg}$. dry $\mathrm{wt} / \mathrm{l}$., for $5 \mathrm{~h}$. in aerated $2 \mathrm{~mm}-\mathrm{K}$ hydrogen phthalate buffer $(\mathrm{pH} 5 \cdot 5)$ alone or with $\mathrm{I} \mathrm{mM}-\mathrm{KCl}$. Chloride absorption was then followed using ${ }^{36} \mathrm{Cl}(0 \cdot 01 \mathrm{mCi} / \mathrm{m}$-equiv. $\mathrm{Cl})$. Successive $100 \mathrm{ml}$. samples from the suspension were rapidly filtered with suction through Whatman no. 54 paper, washed with demineralized water, and the mycelium extracted for $24 \mathrm{~h}$. at room temperature with $\mathrm{I} \mathrm{N}-\mathrm{HNO}_{3}$. A portion of the diluted extract was then counted.

To determine the chemical form of absorbed ${ }^{36} \mathrm{Cl}$, the mycelium was quickly frozen to $-18^{\circ}$ after exposure to the isotope, then thawed and refrozen several times and finally extracted in demineralized water. A portion of the extract was counted and the remainder applied to tandem $5 \mathrm{ml}$. beds of Dowex $50 \mathrm{~W}\left(\mathrm{H}^{+}\right)$and Dow'ex I (formate) exchange resins, and followed by several bed vol. of water. The cation exchanger was then eluted with $4 \mathrm{~N}-\mathrm{NH}_{4} \mathrm{OH}$ : the anion exchanger was eluted successively with $4 \mathrm{~N}$-formic acid and I N-HCl. The eluates were taken to small volume in vacuo and portions counted.

$\mathrm{Na}^{36} \mathrm{Cl}$ was purchased from Amersham-Searle Corporation (Canada) and counted with a Packard Tri-Carb model 300 I liquid scintillation spectrometer, using the second solution of Bruno \& Christian (196I) as liquid fluor. All chemicals were of analytical grade.

\section{RESULTS}

The $\mathrm{Cl}^{-}$content of freshly harvested mycelium was too small for accurate determination by coulometric titration, but did not exceed $0.5 \mu$ equiv./10o mg. dry weight. Freshly harvested mycelium absorbed $\mathrm{Cl}^{-}$slowly (cf. Budd, 1969a), but after several hours aeration in water or buffer at $\mathrm{pH} 5.5$ rapid $\mathrm{Cl}^{-}$uptake took place on transfer to $\mathrm{KCl}$ solutions (Fig. I). 
In other experiments equilibrium with external $\mathrm{KCl}$ at $0 \cdot \mathrm{I} \mathrm{mM}$ was not attained within $8 \mathrm{~h}$. Loading the mycelium with unlabelled $\mathrm{KCl}$ during part of the preincubation period immediately decreased the rate of ${ }^{36} \mathrm{Cl}^{-}$uptake (Fig. I $a$ ). Virtually all of the isotope recovered from frozen and thawed mycelium was in the form of $\mathrm{Cl}^{-}$ion, as judged by its binding only to anion exchanger and release by $\mathrm{HCl}$ but not by formic acid. Since Ioo mg. mycelial dry matter would have contained approximately $0.25 \mathrm{ml}$. intracellular water, the intracellular $\mathrm{Cl}^{-}$concentration after $3.5 \mathrm{~h}$ (Fig. I $a$ ) exceeded the external concentration by $600-$ to 700-fold.
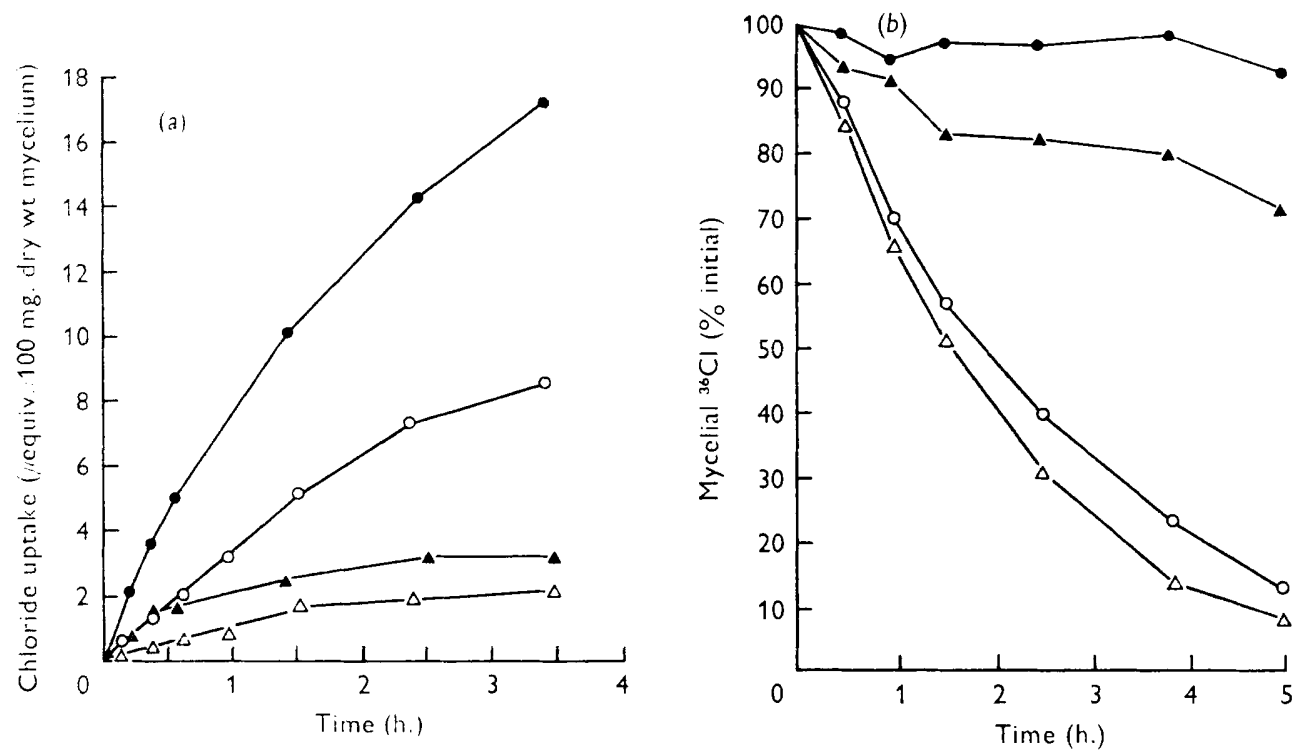

Fig. I (a). The effect of glucose on the uptake of chloride by mycelium pretreated in the absence or presence of $\mathrm{KCl}$. After preincubation and pretreatment in $2 \mathrm{mM}-\mathrm{K}$ phthalate buffer (pH 5.5) or $2 \mathrm{mM}-\mathrm{K}$ phthalate buffer plus $\mathrm{I}$ mM unlabelled $\mathrm{KCl}$, the mycelium was filtered and resuspended in either $0.1 \mathrm{~mm}-\mathrm{K}^{36} \mathrm{Cl}$ or $0.1 \mathrm{~mm}-\mathrm{K}^{36} \mathrm{Cl}$ plus $0.5 \%(\mathrm{w} / \mathrm{v})$ glucose. 9 , Mycelium pretreated in the absence of $\mathrm{KCl}$ and then incubated in $\mathrm{K}^{36} \mathrm{Cl}$; $\mathrm{O}$, mycelium pretreated in $\mathrm{KCl}$ and then incubated in $\mathrm{K}^{36} \mathrm{Cl} ; \Delta$, mycelium pretreated in the absence of $\mathrm{KCl}$ and then incubated in $\mathrm{K}^{36} \mathrm{Cl}$ plus glucose; $\triangle$, mycelium pretreated in $\mathrm{KCl}$ and then incubated in $\mathrm{K}^{36} \mathrm{Cl}$ plus glucose.

(b). The effect of glucose on the outflow of chloride. After harvesting and $3.5 \mathrm{~h}$. aeration in

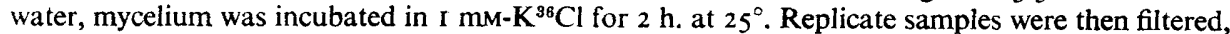
washed by resuspension in water, filtered and resuspended in one of the following solutions: demineralized water $(\mathbf{O})$, I $\mathrm{mm}-\mathrm{KCl}(\boldsymbol{\Delta}), 0.5 \%(\mathrm{w} / \mathrm{v})$ glucose $(\mathrm{O})$ and $0.5 \%(\mathrm{w} / \mathrm{v})$ glucose plus I $\mathrm{mm}-$ $\mathrm{KCl}(\triangle)$. The mycelium at the beginning of the outflow period contained i $5 \mu$ equiv. $\mathrm{Cl}^{-/} / \mathrm{r} 00 \mathrm{mg}$. dry wt.

When glucose was in the uptake medium, ${ }^{36} \mathrm{Cl}^{-}$uptake immediately decreased, whether or not the mycelium was loaded with unlabelled $\mathrm{Cl}^{-}$during preincubation. In Fig. I $a$, comparison of the third curve with the first curve, and the bottom curve with the second curve, shows that over the first $30 \mathrm{~min}$. glucose decreased net ${ }^{36} \mathrm{Cl}^{-}$uptake by approximately $60 \%$ in both the loaded and non-loaded mycelia. Mannitol at the same concentration $(0.5 \%, \mathrm{w} / \mathrm{v})$ as glucose in Fig. I $a$ had no effect on $\mathrm{Cl}^{-}$uptake for at least $90 \mathrm{~min}$. Fructose, however, acted like glucose.

In other experiments similar to that of Fig. I $a$, uptake of ${ }^{36} \mathrm{Cl}^{-}$by non-loaded mycelium was reversed after $\mathrm{I} h$. by the addition of $0.5 \%(\mathrm{w} / \mathrm{v})$ glucose. The retention of absorbed ${ }^{36} \mathrm{Cl}^{-}$by the mycelium was therefore examined (Fig. I $b$ ). Negligible ${ }^{36} \mathrm{Cl}^{-}$outflow took place to water only, and only about $25 \%$ to I $\mathrm{mm}$ unlabelled $\mathrm{KCl}$ after $5 \mathrm{~h}$. Glucose at $0.5 \%(\mathrm{w} / \mathrm{v})$, 
in the presence or absence of I mM unlabelled $\mathrm{KCl}$, promoted rapid ${ }^{36} \mathrm{Cl}^{-}$loss, which was almost quantitative after $5 \mathrm{~h}$. Mannitol at $0.5 \%(\mathrm{w} / \mathrm{v})$ had no effect in a parallel experiment (not shown).

\section{DISCUSSION}

The negligible $\mathrm{Cl}^{-}$content of freshly harvested mycelium in these experiments ensures that ${ }^{36} \mathrm{Cl}^{-}$uptake is net and does not include significant isotopic exchange. Chloride is evidently accumulated from dilute $\mathrm{KCl}$ and, assuming an internal negative membrane potential at the mycelial surface (cf. Slayman, $1965 a, b$ ), this represents active transport. The decrease in $\mathrm{Cl}^{-}$uptake by glucose, which is the carbon source used for growth, is, therefore, unexpected. Glucose could inhibit net $\mathrm{Cl}^{-}$uptake either by decreasing $\mathrm{Cl}^{-}$influx or by promoting $\mathrm{Cl}^{-}$outflow. That $\mathrm{Cl}^{-}$influx is decreased is indicated by the observation that glucose inhibits ${ }^{36} \mathrm{Cl}^{-}$uptake over the first $30 \mathrm{~min}$. to the same extent in mycelium loaded with unlabelled $\mathrm{Cl}^{-}$as in mycelium initially almost devoid of $\mathrm{Cl}^{-}$. If glucose acted only by causing outflow of $\mathrm{Cl}^{-}$ions after their entry, the isotopic dilution of entering ${ }^{36} \mathrm{Cl}^{-}$in the loaded mycelium should slow the loss of isotope as compared to non-loaded controls. The apparent glucose inhibition would therefore be smaller in loaded mycelium. This is not observed.

The results of Fig. I $a$ do not exclude an influence of glucose on $\mathrm{Cl}^{-}$outflow, and Fig. I $b$ shows that this is promoted in the presence of glucose. Inhibition of net $\mathrm{Cl}^{-}$uptake by glucose is therefore the sum of its effects on entry and outflow. How these effects are mediated is not known, but they cannot be simply an osmotic effect, since mannitol at the same osmolarity as glucose has no influence on $\mathrm{Cl}^{-}$entry or outflow for at least $90 \mathrm{~min}$. The inhibition of net $\mathrm{Cl}^{-}$uptake might be due to the sugar molecule itself or to some metabolite.

The phenomenon of inhibition of halide uptake by glucose could be a general one but to the authors' knowledge it has previously been reported only for Chlorella (Paschinger \& Broda, 1967).

This work was supported by an operating grant from the National Research Council of Canada.

\section{REFERENCES}

Bruno, G. A. \& ChristiAn, J. E. (196I). Determination of carbon-I4 in aqueous bicarbonate solutions by liquid scintillation counting technique. Analytical Chemistry 33, 1216-12 I8.

BuDd, K. (1969a). Potassium transport in non-growing mycelium of Neocosmospora vasinfecta. Journal of General Microbiology 59, 229-238.

BuDd, K. (1969b). The assimilation of bicarbonate by Neocosmospora vasinfecta. Canadian Journal of Microbiology 15, 389-398.

Conway, E. J. \& Downey, M. (1960). An outer metabolic region of the yeast cell. Biochemical Journal 47, $347-355$.

Paschinger, H. \& Broda, E. (1967). Hemmung der aktiven Bromidaufnahme durch Pflanzenzellen durch Glucose. Monatshefte für Chemie und verwandte Teile anderer Wissenschaften 98, 905-910.

Rothstein, A. (1965). The Fungi: an Advanced Treatise. Edited by G. C. Ainsworth \& A. S. Sussman, vol. I, pp. 429-455. New York: Academic Press.

Slayman, C. L. (1965a). Electrical properties of Neurospora crassa. Effects of external cations on the intracellular potential. Journal of General Physiology 49, 69-92.

Slayman, C. L. $(1965 b)$. Electrical properties of Neurospora crassa. Respiration and the intracellular potential. Journal of General Physiology 49, 93-1 16. 